\title{
Green Computing
}

\author{
A.M. Bagul ${ }^{1}$, Saylee Shitole ${ }^{2}$ \\ Professor, Computer Department, NBN Sinhgad School of Engineering, Pune ${ }^{1}$ \\ Student, Computer Department, NBN Sinhgad School of Engineering, Pune ${ }^{2}$
}

\begin{abstract}
The concept of green computing is for the environmental impact and eco friendly nature . it also use of manufacturing purpose, for use of study and use for disposing of computing devices and there resources etc., green computing is also called as green technology. Green computing is the environmentally responsible use of computers and related resources. The goal of green computing is related to green chemistry, it reduces the risky material, it use to increases a energy efficiency during product lifetime. Green computing is the study and practice of energy efficient and eco-friendly use of computer. The principle behind energy efficient coding is to save power by getting software to make less use of the hardware, rather than continuing to run the same code on hardware that uses less power.
\end{abstract}

Keywords: Environmental impact, Green Computing, Green ICT, Green IT.

\section{INTRODUCTION}

Green is a English word which is used to describe a colour which is a mixture of yellow and blue. Green computing is nothing but the environmentally impact which is use for human related resources. Green computing is nothing but the green IT which is called as information technology The aim of the green computing a related to green chemistry. Decrease the use of risky material, it also use for high maximize energy efficiency of product lifetime. Green computing is work for the environment. Green computing focused on reducing the ecological impact of an industry and growing earth population. Green computing is the ecological utilization of computer and there resources. Green computing in the united states was the labelling programs called as energy star. the green electronics council offers the electronics' product environment assessment tool to purchase the "green" computing system. So hence green computing is use for the reusability of their many product. The principle behind energy efficient coding is to save power. So green computing is nothing but the green technology which is widely use for energy IT application.

\section{PROCESS OF GREEN COMPUTING}

There are five process are used in green computing. The first phase of green computing describe that specification. This phase indicates that the current green computing initiatives and also used for to implement the green data Centers. The second phase of green computing is the design. Its used to defines that how to design the data. the third phase of green computing is implementation and usage. It tells that the implementation of green computing decision and usage of IT resources like, computer, peripheral and some subsystem.

The fourth phase of the green computing is the recycling. This phase covers the disposal and recycling of material. And the last phase of the green computing analysis which is related to measuring the performances of data Centers.

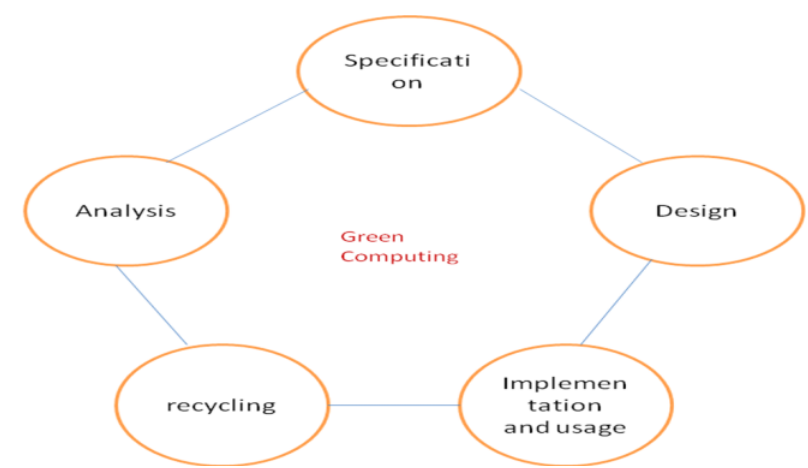

Figure. Process diagram of green computing

\section{NEED OF GREEN COMPUTING}

Green computing whose target are to reduce the use of risky materials, maximize energy efficiency during the product's lifetime, and increases the recyclability of products. We can use Green Computing for following manner:-

1) Using ENERGY STAR, this products are help in energy conversion of green computing.

2) The Climate Savers Computing Initiative (CSCI) can be used for selecting green products.

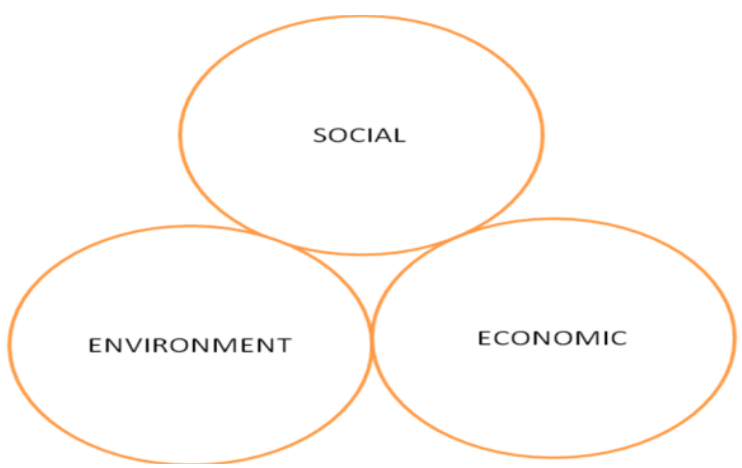

Figure. Venn Diagram of Green Computing 


\section{APPROCHES TOWARDS GREEN COMPUTING}

\section{VIRTUALIZATION}

Computer virtualization refers to the abstraction of computer resources, such as the process of running two or more logical computer systems on one set of physical hardware. the PC virtualization is process of abstraction of PC assets. With the help of virtualization system administrator can combine few physical machine into virtual machine on a single chip.

\section{Energy Star}

Energy star is worldwide standard for the energy efficient which is originating from United States Of America. Gadgets are conveying the energy star logo likewise PC items and peripherals and kitchen applications.

Energy star items are:

1) Home application

2) Servers

3) Computers

\section{EFFORTS TO IMPLEMENT GREEN COMPUTING}

We do not need to stop using computer system and power to save our environment. so that's why we have to make some effective efforts by adapting green technology. By adapting following tips we can go green to make our environment healthy:

1. Purchase energy star labelled product : with the help of energy star, the manufacturing of various electrical and electronics equipment ensures less power consumption. Hence we need to use monitors and air conditioners with energy star label to go green.

2. Unplug the electronics appliances when not in use: Various experts says that most of the plugged in electronic gadgets uses low amount of electricity, but some other electronics devices like computer systems and television sets consumes a lot of electricity even when they are in standby mode. we need to unplug various electronics devices when they are not in use to save money and electricity.

\section{NEED OF GREEN COMPUTING}

Computer systems are becoming a more progressively everywhere. It's a part of global infrastructure. It has resulting in large installation of computing devices to provide multiple devices. So overall harm due to the factors can be widely divided into three categories:

\section{- Manufacturing process}

During the Manufacturing process there are many toxic materials are used like chromium, lead and cadmium etc. which are quite harmful for human being and nature. So another material like mercury is also used in medical equipment, data transmission material, etc. so apart from these three there exit lot of toxic materials like hexavalent chromium and PVC plastics etc.

\section{- Destruction process}

The small component like monitor, CPU etc are they use a many toxic material which are harmful for nature. there are different types of gases and liquid are produced from different toxic material. So with the help of destruction process. we may not give more attention towards the proper disposal off E- wastage.

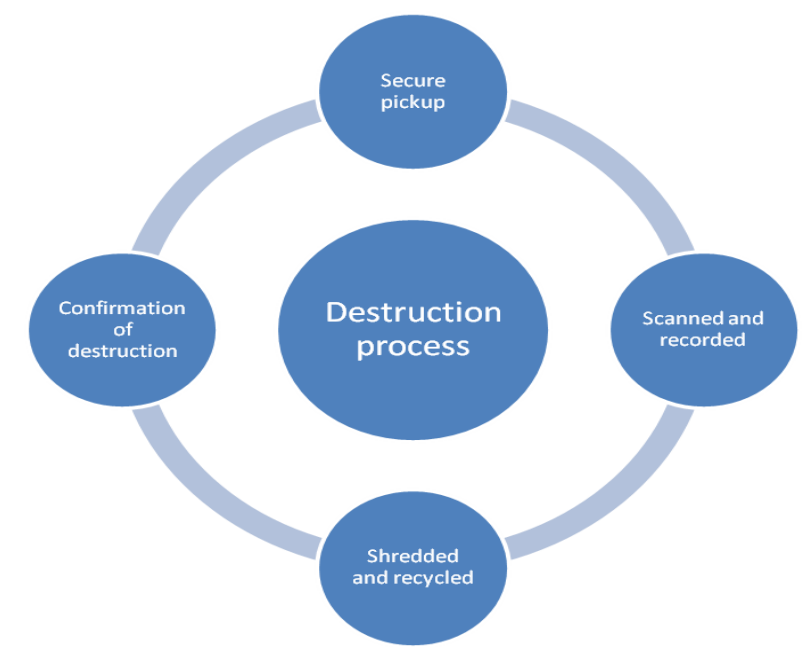

The above diagram shows the destruction process of green computing

\section{CONCLUSIONS}

With help of these devices the human life is going to more comfortable and enjoyable. So with the help of green computing, we can use many technology to avoid an environmental impact. Nowadays every computer manufacturing concept is focusing on the green IT concept. it can be seen people moving towards the green technology day by day . this review provides an overview of importance of green computing. Green computing gain lot of importance rise in power consumption and its impact on environment. This paper shows the need of green computing regarding environmental impact. This paper suggested some beneficial tips that follow from today for now for greener tomorrow.

\section{REFERENCES}

[1] Priya Rana, International Journal of Advanced Computer and Mathematical Sciences December 2010- Green Computing Saves Green

[2] Y K. Ganesh (McKinsey \& Company, India), International Journal of Green Computing (IJGC) October 20th,2012- Reach Your Environmental Goals With Green Computing.

[3] "Kyoto Protocol." Compton's by Britannica. Britannica Online for Kids. Encyclopædia Britannica, Inc., 2016. Web. 9 Apr. 2016.

[4] Ms. Swati Aggarwal, Mrs. Monika Garg, Mr. Pramod Kumar, International Journal of Emerging Technology and Advance Engineering, February 2012- Green Computing is Smart Computing - A Survey. 